Cahiers $d u$ MONDE RUSSE

\section{Cahiers du monde russe}

Russie - Empire russe - Union soviétique et États indépendants

$43 / 4 \mid 2002$

Intellectuels et intelligentsia

\title{
Vladimir Malahov, Skromnoe obajanie rasizma i drugie stat'i |V. S. Malahov, V. A. Tiškov, eds, Mul 'tikul'turalizm i transformacija postsovetskih obščestv
}

\section{Mischa Gabowitsch}

\section{OpenEdition}

Édition électronique

URL : https://journals.openedition.org/monderusse/4047

DOI : $10.4000 /$ monderusse.4047

ISSN : $1777-5388$

Éditeur

Éditions de l'EHESS

\section{Édition imprimée}

Date de publication : 30 décembre 2002

Pagination : 770-

ISBN : 2-7132-1796-2

ISSN : $1252-6576$

Référence électronique

Mischa Gabowitsch, « Vladimir Malahov, Skromnoe obajanie rasizma i drugie stat'i I V. S. Malahov, V. A. Tiškov, eds, Mul'tikul'turalizm i transformacija postsovetskih obščestv », Cahiers du monde russe [En ligne], 43/4 | 2002, mis en ligne le 06 juillet 2009, consulté le 03 septembre 2022. URL : http:// journals.openedition.org/monderusse/4047 ; DOI : https://doi.org/10.4000/monderusse.4047

Ce document a été généré automatiquement le 3 septembre 2022.

Tous droits réservés 


\title{
Vladimir Malahov, Skromnoe obajanie rasizma i drugie stat'i | V. S. Malahov, V. A. Tiškov, eds, Mul 'tikul'turalizm i transformacija postsovetskih obščestv
}

\author{
Mischa Gabowitsch
}

\section{RÉFÉRENCE}

Vladimir MALAHOV, Skromnoe obajanie rasizma i drugie stat'i (Le charme discret du racisme et autres articles). Moscou, Dom intellektual'noj knigi \& Modest Kolerov, 2001, $176 \mathrm{p}$.

V. S. MALAHOV, V. A. TIŠKOV, eds, Mul'tikul'turalizm i transformacija

postsovetskih obščestv (Le multiculturalisme et la transformation des sociétés postsoviétiques). Moscou, Institut etnologii i antropologii RAN, 2002, 356 p.

1 S'il est actuellement de nouveau à la mode de valoriser l'aspect multiculturel et multinational de la Russie et, rétrospectivement, de l'empire russe, les diverses variantes $\mathrm{du}$ discours «multiculturaliste» (canadien, américain, allemand, australien, etc.) n'avaient guère, jusqu'à une date récente, rencontré de réception ni trouvé d'équivalent dans les débats publics en Russie. C'est ce à quoi se proposent de remédier ces deux recueils d'articles. D'emblée, on constate avec soulagement que, loin de copier de manière peu critique un discours occidental à la mode ou de le condamner gratuitement, le philosophe Vladimir Malahov, auteur du premier recueil et éditeur du second, s'est lancé dans un projet d'adaptation critique du concept de multiculturalisme, anticipant une éventuelle lecture simpliste dans le contexte post-soviétique. 
2 Le premier de ces deux volumes (Le charme discret du racisme) offre des articles déjà parus dans des revues et journaux russes et permettant de présenter le multiculturalisme comme l'un des remèdes possibles à la vision primordialiste des nations qui, loin de n'avoir cours que dans l'ethnologie (post-)soviétique, est devenue en Russie une idéologie publique.

3 Partant du constat que le pluralisme culturel ou ethnique, souligné de manière abusive par « l'amitié entre les peuples » soviétique, est aujourd'hui quasi absent de la sphère publique « russienne » (c'est-à-dire celle de la Russie - rossijskij), Malahov passe en revue différents modes de reconnaissance publique de l'altérité et de la pluralité, qu'il replace à chaque fois dans le contexte historique ou philosophique de leur élaboration - qu'il s'agisse de l'institutionnalisation du système multiculturaliste au Canada, de la recherche d'identité parmi les descendants de divers groupes ethniques aux États-Unis, ou encore des divers usages que fait du concept d'identité nationale une pseudo-sociologie qui aime à se déclarer post-moderne. Dans les derniers essais regroupés dans ce volume, Malahov en vient à proposer le terme de "pluralisme culturel» comme alternative au «multiculturalisme» dans le contexte de la Russie actuelle, et conclut en analysant l'exemple concret du mouvement antiraciste en Russie pour illustrer les dangers que crée toute tentative pour établir des droits spéciaux pour les " groupes ethniques ", objets d'une réification comparable à celle qu'opère la définition stalinienne de la nation.

4 Si ce premier ouvrage conclut de manière relativement pessimiste sur l'utilité du concept de multiculturalisme pour la Russie actuelle, la contribution de Malahov au second volume, tout en détaillant à nouveau les dangers d'un multiculturalisme compris comme "dialogue entre les groupes ethniques", précise néanmoins que, lu dans une optique civique d'affirmation de la pluralité, ce concept pourrait être adopté en Russie comme alternative à la politique "mono-culturelle» actuelle qui érige la «culture slavo-orthodoxe »en une dominante du discours public, limitant la Russie à sa dimension russe.

5 Le défi que représenterait cette adoption n'est cependant guère relevé par les co-auteurs de ce second recueil, produit de deux colloques ayant eu lieu en 1999 et 2000. Si les auteurs de la partie théorique du volume et la plupart des auteurs "occidentaux " (Charles Taylor, Christoph Zürcher, William Beeman, Franz-Olaf Radtke et Isabel Diehm) se placent (de manière critique pour les deux derniers) plus ou moins dans le cadre d'un débat sur le multiculturalisme, la majorité des autres participants issus de pays postsoviétiques présentent des études qui s'inscrivent dans leur propres programmes de recherche, ne faisant référence au concept-maitre du volume souvent que de manière superficielle. Pour autant, certaines de ces contributions n'en apportent pas moins des éléments pour éclairer les conditions et les difficultés de l'introduction d'une nouvelle formule exprimant la pluralité culturelle dans l'espace post-soviétique.

6 Notons en premier lieu les observations fort intéressantes des sociologues ol'ga Brednikova et Oleg Pančenkov de Saint-Pétersbourg. Dans un article concis, ils montrent comment l'institutionnalisation, dans le contexte post-soviétique, de « cultures » qui sont censées être les sujets d'un dialogue multiculturel, crée ce qu'on appelle dans la littérature sociologique des «entrepreneurs ethniques»: des représentants d'associations arméniennes, tatares, azéries, etc., qui, hautement russifiés et urbanisés, prétendent néanmoins « représenter » tous les membres de « leur » groupe - alors que ces derniers n'ont pourtant que très peu en commun avec leurs prétendus 
leaders et n'ont pas suffisamment de liens entre eux justifiant leur représentation en tant que groupe.

7 La construction des « ethnies » dans les représentations du social fait également l'objet d'une critique d'Oksana Karpenko, qui analyse le traitement discursif des " gens du Sud » par la presse dite démocratique. Aleksandr Osipov présente une étude détaillée du concept des «droits des groupes»-concept fondamental pour le multiculturalisme militant -, et conclut que ce terme est quasiment absent des textes et de la pratique du droit international, auquel font pourtant souvent référence les tenants d'une introduction de ces droits dans la législation de la Fédération de Russie. Le sociologue Viktor Voronkov, quant à lui, définit rétrospectivement l'URSS comme "le pays du multiculturalisme victorieux " et réfléchit sur le rôle public du chercheur dans un contexte où, à cause de cet héritage même, de nombreux conflits ont tendance à « s'ethniciser » rapidement.

8 En revanche, la contribution qu'apportent au débat des articles portant sur les modèles de coexistence de communautés ethniques retenus en Estonie, au Kazakhstan et au Daghestan (Aleksej Semenov, Enver Kisriev, Igor' Savin) est très limitée. Qu'il s'agisse du bilan détaillé de Kisriev situé dans le cadre théorique de la "démocratie co-sociétale » (soobščestvennaja demokratija: il s'agit d'une démocratie qui tente de représenter les divers éléments ethniques ou confessionnels d'une société) ou du compte-rendu hautement politisé de Semenov, ces études ne nous enseignent rien de fondamentalement nouveau sur les régions en question et surtout restent en dehors de la discussion sur le multiculturalisme censée être l'objet central de cet ouvrage. Si Vladimir Malahov a raison de souligner dans son introduction que le concept de multiculturalisme est vu d'un œil plus positif par les chercheurs des pays baltes et centrasiatiques (qui craignent que la seule alternative n'en soit l'ethnocratie) que par leurs collègues russes, ces divergences ne donnent pas lieu à un débat qui permettrait de comparer les situations dans les différents pays ou républiques.

9 Si certaines des contributions (comme celle, fort intéressante par ailleurs, de Lev Gudkov sur « le néo-traditionalisme et la résistance au changement ») ignorent tout simplement les termes mêmes du débat proposé, d'autres (par exemple le texte d'Aleksandr Sogomonov sur le concept d'" État multi-ethnique » ou l'article de Nikolaj Ragozin sur "l'interculturalité» dans l'enseignement des droits de l'homme, juxtaposé aux réflexions d'Isabel Diehm sur l'expérience de l'enseignement multiculturel dans les écoles de Francfort à haute proportion d'enfants d'immigrés) retombent sur des concepts plus enracinés dans le discours sur la politique et les droits de l'homme en Russie que ne l'est le « multiculturalisme».

10 Le co-éditeur du volume, Valerij Tiškov, directeur de l'Institut d'ethnologie et d'anthropologie de l'Académie des sciences, voit le débat sur le multiculturalisme dans l'optique de sa lutte pour une redéfinition civique de la nationalité en Russie. Dans sa conclusion, il s'affirme critique non seulement à l'égard du cloisonnement des "cultures" qu'implique un multiculturalisme appliqué aux groupes et non pas aux individus, mais également à l'égard de la notion du " surplus de culture » que véhiculait le modèle soviétique et qui donne lieu actuellement à une nostalgie de la culture (ou des cultures) visant à conserver à tout prix des formes de production culturelle liées aux « nationalités » établies.

11 Reste à savoir si les nombreuses pistes de recherche et de discussion ouvertes par ce volume seront reprises à l'avenir. Si le recueil d'articles de Malahov a déjà connu un 
certain succès dans les milieux intellectuels de Moscou et de Saint-Pétersbourg, le faible tirage du second volume (500 exemplaires contre 1000 pour le premier) n'est pas fait pour faciliter la diffusion du débat sur la meilleure forme de pluralité culturelle en Russie. Il faut ajouter, malheureusement, que les deux volumes sont édités avec très peu de soin: ils multiplient les fautes de frappe et les imprécisions dans les références bibliographiques, ce qui, dans le cas d'ouvrages étrangers, risque parfois de rendre l'accès à ces textes difficile pour les lecteurs russes désirant s'initier aux débats occidentaux sur le multiculturalisme. Manque aussi une présentation des auteurs de l'ouvrage collectif, ne serait-ce que l'indication de leurs institutions de rattachement. 